\title{
Mcewan, Ian. Enclausurado. Tradução de Jorio Dauster. São Paulo: Companhia das Letras, 2016, 200 p.
}

Marcia Goretti Carvalho 1

ŁUniversidade Federal do Pará, Belém, Pará, Brasil

Ian McEwan, ficcionista importante de sua geração, recebeu vários prêmios, como o Man Booker por Amsterdam em 1998. Autor de best-sellers como Nutshell, em 2016, romance ficcional que foi publicado, no Brasil, pela Companhia das Letras, com o título Enclausurado, traduzido por Jorio Dauster. Em Enclausurado, temos um narrador-feto, sem nome, que constrói a personalidade dos personagens junto com o leitor. Leitura atraente, com momentos de tragédia e discussões sobre a humanidade e a realidade da sociedade.

Enclausurado pode ser considerado uma comédia filosófica, com uma narrativa fantástica e com referências a Hamlet, de William Shakespeare como as personagens Trudy e Claude (Gertrudes e Claudis em Hamlet) e a trama central da história, envolvendo traição, vingança e assassinato além de citações sobre poesia na obra. A epígrafe do livro foi extraída de Hamlet e traduzida, literalmente, para o português.

O narrador-feto, inteligente e sagaz, narra a traição de sua mãe, Trudy, com seu tio, Claude que pretendem matar John, seu pai, para ficar com a herança. Sendo a única testemunha, o feto tenta evitar o crime e depois vingá-lo. Nesse ínterim, ele tem opiniões 
críticas sobre seu país e o mundo, assuntos atuais conhecidos pelos brasileiros através da imprensa, como os refugiados na Europa, o terrorismo e outros temas atuais.

Com detalhes minuciosos e poéticos, o narrador descreve os principais personagens como sua mãe Trudy "[...] 'cachos revoltos' até seus 'ombros brancos como a polpa de uma maçã', [...] nariz "é um botão de madrepérola', [...]" (Enclausurado, 15), seu relacionamento com ela, seu amor pelo seu pai e desprezo pelo seu tio. Descreve a casa de seus pais e sua casa, o ventre de sua mãe, e geralmente usa o pronome "nós", referindo-se a sua mãe e a ele: “[...] Estamos nos embebedando [...]” (Enclausurado, 42). O narrador-feto tem senso de humor sarcástico como nos exemplos abaixo, em que o tradutor "captou" o sarcasmo do autor e para o leitor-alvo, o público brasileiro:

[...] Small talk or a trade in threat and insult-I lack the social experience to know. (Nutshell, 66)

[...] Conversa fiada ou uma troca de ameaças e insultos me falta experiência social para saber. (Enclausurado, 74)

[...] Baby and house sale,

[...] Only syntax might make one think that I'm for sale. (Nutshell, 159)

[...] Bebê e a casa à venda,

[...] Só a sintaxe pode fazer alguém pensar que estou à venda[...].(Enclausurado,163)

O linguajar poético e o dramático do texto são atrativos e "transcriados" na tradução em português: “[...] O crime, [...], uma estátua fria de pedra numa clareira da floresta. [...] Trudy fugindo por uma trilha coberta de geada. [...]" (Enclausurado, 125). As cenas de sexo de Trudy e Claude são descritas minuciosamente com lirismo tanto no texto de partida como na tradução para português (no Brasil). Dentre tantas discussões de "adultos", há algumas 
envolvendo religião, sentimentos humanos (como a vingança e o egocentrismo), política, filosofia, arte e ciência.

Quanto aos elementos paratextuais, no $e$-book Kindle da Amazon, a capa é ilustrada com uma obra de Leonardo da Vinci "Cinco vistas de um feto no útero" e a menção de que Nutshell é do mesmo autor de Atonement. Na tradução brasileira, a capa é ilustrada com uma folha de papel escrita e amassada, semelhante a uma casca de noz, com o título do livro e o nome do autor. O nome do tradutor está na folha de rosto. A estrutura do texto de partida e da tradução brasileira apresentam vinte capítulos e o conteúdo semântico de cada capítulo é rigorosamente o mesmo na obra traduzida.

Nos cinco primeiros capítulos, um feto de nove meses, enclausurado no útero, é o narrador da história. Ele descreve sua morada, critica o mundo dos adultos, conhece e aprecia vinho e poesia, descreve sua mãe, Trudy, seu tio, Claude, e seu pai, John Cairncross, que saiu de casa. $\mathrm{O}$ feto, nesse momento da narrativa, tenta escutar a trama macabra que envolve seu amado pai. O narrador odeia seu tio. Escuta, finalmente, o plano de traição: envenenar John com uma bebida. $\mathrm{O}$ feto fica desapontado com sua mãe.

Enquanto o narrador filosofa sobre o mundo atual, Claude vai ao escritório de John para emprestar-lhe dinheiro. John comenta com Claude a intenção de retornar para Trudy e sobre Elodia, uma poeta amiga John. Claude ouve tudo indiferentemente.

O tradutor ora emprega a tradução literal ora "domestica" o texto de chegada como em "ignorantão" com equivalentes criados, ou adaptações como no trecho abaixo, trazendo o texto meta para mais próximo da realidade do leitor. Alguns trechos desses capítulos:

Europe, [...] weak [...], immigrant populations languishing, [...] inequalities of wealth, [...]China, [...], planning for the war [...]. Muslim-majority countries plagued by reli- 
gious puritanism, by sexual sickness, [...] The Middle East, fast-breeder for a possible world war. [...], the United States, [...], guilty of torture, [...]., [...]. Africa [...]. Its children dying, [...], for want of easy things [...] altered climate, vanishing forests, [...]. (Nutshell, 24)

[...] Europa, [...], fragilizada [...] imigrantes apodrecendo [...]. novas desigualdades de riqueza [...] China, [...], preparando-se para a guerra [...] muçulmanos sofrendo os males do puritanismo religioso, da repressão sexual, [...] O Oriente Médio capaz de gerar uma guerra mundial. [...] Estados Unidos, [...], culpados de praticar torturas, [...], [...] África [...]. Seus filhos morrendo [...] por falta de coisas simples [...] mudança climática, do desaparecimento das florestas, [...]. (Enclausurado, 32-34)

(sobre seu tio Claude) [dull-brained yokel] (Nutshell, 19) [...] ignorantão [...] (Enclausurado, 27)

(sobre sua mãe Trudy) [For being selfish, devious, cruel.] (Nutshell, 15)

[...] egoísta, malvada, cruel. (Enclausurado, 22-23)

(sobre seu pai John). [...] he is a poet without recognition[...]owns [...]an impoverished publishing house[...]. (Nutshell, 10)

[...] um poeta sem renome [...] proprietário [...] de uma editora [...]. (Enclausurado, 19-20)

(sobre o plano de Trudy e Claude) [...] kill John Cairncross, sell his birthright [...], share the money, dump the kid. [...]. (Nutshell, 46)

[...] matar John Cairncross, vender o que era dele [...], dividir o dinheiro, abandonar o menino. [...]. (Enclausurado, 55) 
John chega à casa de Trudy com Elodia. John relembra seu relacionamento com Trudy e confessa que sabe dela com o irmão. John quer a casa de volta e voltará na manhã seguinte. Os amantes repassam os detalhes. John chega. Trudy convida para um café. Claude chega com uma vitamina envenenada. Trudy oferece mais café, parecendo evitar o crime. Enquanto John e Trudy conversam, Claude planta provas de um suicídio no carro de John. Finalmente Claude oferece uma vitamina a John que aceita e vai embora no carro. O plano se concretiza. Alguns trechos desses capítulos:

So all traces [...] must be eradicated, cleaned to extinction, every last hair [...]. (Adaptação) (Nutshell, 57)

[...] vestígios [...] eliminados, [...], sem sobrar nem mesmo um fio de cabelo [...] (Enclausurado, 65-66).

Dead within hours. [...]. Chemistry without mercy, purpose or regrets. [...] (Nutshell, 98)

Morto em poucas horas. [...]. A química sem piedade, propósito ou remorso. [...] (Enclausurado, 105).

A polícia vai à casa de Trudy para lhe comunicar o falecimento de John. Ela se desespera, ou finge, e o policial fala em suicídio. Trudy e Claude combinam os seus depoimentos, reforçando a hipótese de suicídio por causa da depressão de John. Trudy acha Claude egoísta e interesseiro. O feto quer vingança, tentando suicidar-se com o cordão umbilical. O narrador sente-se triste pela indiferença de sua mãe. Elodia vai à casa de Trudy para expressar seus sentimentos e convidá-la para uma homenagem póstuma a John. Trudy e Claude procuram convencer Elodia do suicídio por conta da depressão de John. Elodia parece convencida da hipótese de suicídio e vai embora.

Claude pensa em fazer as malas, porém Trudy começa a sentir tonturas e arrependimento pelo crime. A Inspetora-chefe Allison quer conversar com eles na casa de Trudy. Eles ficam preocupados por- 
que virou um caso policial. Allison chega, inspeciona a casa, faz perguntas intrigantes aos dois. A policial vai voltar no dia seguinte. Trudy e Claude ficam apavorados e planejam fugir para o exterior. Trudy entra em trabalho de parto. Claude só pensa nos passaportes e no dinheiro. Nasce o bebê. Eles perderam o trem para fuga. $\mathrm{O}$ bebê, vingado, atrapalhou a fuga dos assassinos. O interfone toca. Uma reflexão filosófica do narrador-bebê "fecha" o romance, uma "comédia filosófica":

[...] first sorrow, then justice, then meaning. The rest in chaos. (Nutshell, 197)

[...] primeiro a tristeza, depois a justiça, enfim o significado. O resto é caos. (Enclausurado, 199)

Em relação ao processo tradutório, Jorio Dauster procurou reproduzir na língua do receptor (português) o equivalente mais próximo possível da mensagem da língua fonte (inglês) em termos de estilo e significado. Fez escolhas para aproximar mais a trama de McEwan do leitor brasileiro. Ele inicia o primeiro capítulo com a mesma construção sintática do original: "So here I am, upside down in a woman" (Nutshell, 1); "Então aqui estou, de cabeça para baixo, dentro de uma mulher" (Enclausurado, 9). Uma tradução literal em alguns trechos da narrativa e uma tradução livre em outros, resultando em um texto mais "compreensível" ao leitor brasileiro.

As escolhas lexicais e sintáticas feitas pelo tradutor se adequaram ao português brasileiro como a tradução de fraseologismos. Nomes próprios, expressões em línguas estrangeiras, palavras ou expressões em itálico ou entre aspas e repetições se mantiveram na tradução como na obra original. A manutenção das repetições, das aspas e do itálico é um recurso estilístico para destacar a ênfase e a ironia expressas pelo autor da obra original. 
a) Uso do itálico:

"Como é que eu, [...], posso saber tanto [...] eu escuto. [...]." (Enclausurado, 12) - algo improvável um feto "escutar", mas na narrativa o feto escuta e filosofa.

No texto-fonte: "How is it that [...] could know so much, [...], I listen [...]." (Nutshell, 4)

“[...] Claude disse [...]: "Podemos". E depois de um instante de reflexão: "Podemos, sim" (Enclausurado, 17). No texto-fonte "[...] Claude said flatly, "We can". And then, [...] "We can" (Nutshell, 9). O "sim" enfatiza o "podemos";

"Ele está morto" (Enclausurado, 120) = "He's dead" $(\mathrm{Nu}$ tshell, 114). No destaque da palavra "morto" demonstra que isso é grave para Trudy;

b) Repetições:

"[...] mas nos demos muito beeeeem" (Enclausurado, 122). No texto-fonte: "[...] but we came throuuugh" (Nutshell, 116);

"[...] No entanto. No entanto. [...]" (Enclausurado, 126). No texto-fonte: “[...] And yet. And yet. [...]" (Nutshell, 120);

c) Lugares em Londres e no mundo com a ortografia do inglês ou do português: St. John's Wood, Judd Street, Hamilton Terrace, Paquistão, África, Israel, Rússia, etc.;

d) As palavras e expressões estrangeiras foram mantidas com a mesma grafia que aparecem no texto-fonte: coup de vérité, folie à deux, memento mori, etc. (Nutshell, 13;79;51) 
e) Os nomes de personagens e de personalidades foram mantidos com a mesma grafia que aparecem no texto-fonte: Trudy, Claude, John Cairncross, Elodia, Schubert, Barthes, Kant, Platão, Heaney, Keats, Owen, Stálin e outros;

f) As marcas de bebida foram mantidas com a mesma grafia que aparecem no texto-fonte: Sancerre, Romanée-Conti, Pinot Noir, etc. (Nutshell, 6;51);

g) O tradutor fez a conversão do sistema de medidas britânico para o sistema de medidas brasileiro: "um metro e noventa" (Enclausurado, p. 23) - "six foot three"(Nutshell, 15); "Uns trezentos e vinte quilômetros." (Enclausurado, 73) - "About two hundred miles" (Nutshell, 65), etc.;

h) Os fraseologismos foram traduzidos para o português brasileiro de acordo com o conhecimento do leitor brasileiro, "domesticando" a tradução:

"many hands make..." (Nutshell, 85) > "Deus ajuda a quem..." (Enclausurado, 42);

"as a doornail" (Nutshell, 114) > "mortinho da silva" (Enclausurado, 120);

"The naked truth" (Nutshell, 119) > "A verdade nua e crua" (Enclausurado, 125);

"Cutting off your nose to spite another's face" (Nutshell, $122)>$ "Prejudicar-se para prejudicar o outro" (Enclausurado, 128);

"I've pins and needles in my legs" (Nutshell, 127) > "as pernas formiguem" (Enclausurado, 132);

"the catch is in the keep-net" (Nutshell, 152) > "o peixe caiu na rede." (Enclausurado, 157);

Observa-se a supressão ou acréscimo de palavras, frases ou fragmentos de frases na tradução. Em alguns casos pela dificuldade de 
tradução ou por não ser necessária a tradução e, em outros casos, para melhorar a compreensão do texto. Vejamos alguns exemplos abaixo:

a) "a slab of unsalted butter" (Nutshell, 17) > "um tablete de manteiga sem sal comprado no campo" (Enclausurado, 25), com acréscimo de "comprado no campo";

b) “'Blood-wise fatal bellman', he starts. He likes a trochaic trimeter." (Nutshell, 36) > "Fatal porteiro, sanguinolento', ele começa." (Enclausurado, 44), com supressão de "He likes a trochaic trimeter.";

c) "youngly slumped (I insist on the adverb) across the table" (Nutshell, 46) > "uma jovem derreada sobre a mesa" (Enclausurado, 54), supressão dos parênteses (redução); "hide in forensic smears among the chaos" (Nutshell, 137) $>$ "se ocultam em meio ao caos" (Enclausurado, 142), com supressão de "in forensic smears";

d) "Not by my mother's expensively constrained vowels." (Nutshell, 169) > "Não pelas vogais forçadas de minha mãe, aprendidas em colégios caros." (Enclausurado, 174), com acréscimo de "aprendidas em colégios caros";

Para finalizar, percebe-se o uso do palavrão "porra", nas falas de Claude, como escolha do tradutor para palavras com outro sentido possível e a manutenção do apelido sugestivo de Trudy usado por Claude (ratinha - "mouse"). Algumas poucas frases com problemas na interpretação como em "As beneficiary of his will" (Nutshell, 57), foram traduzida por "Como beneficiária da herança de Claude" (Enclausurado, 65), mas, na realidade, eram "herança de John". 
"Let's hope that bloody [maldito] car starts." (Nutshell, 99) = "Tomara que a porra desse carro pegue" (Enclausurado, 106).

“Oh, dear..." (Nutshell, 102) = "Porra!" (Enclausurado, 109)

Em Enclausurado, o narrador-feto pode ser considerado um alter ego de McEwan, abordando temas atuais como refugiados, terrorismo, riqueza, miséria, violência, ser humano. Isso em tom narrativo e prosa poética irônica com linguagem rica e contemporânea, personagens complexos, enredo de contextos humanos e intertextualidade, exigindo conhecimento prévio do leitor. O decorrer dos acontecimentos é instigante pelas ações e reflexões do livro com muita ironia e poesia. O leitor fica curioso e em suspense pelo destino de Trudy e Claude em um final inconclusivo, terminando a narrativa com uma reflexão filosófica do narrador-bebê como no início filosófico do romance.

O tradutor realizou, de um modo geral, uma tradução com excertos mais "domesticados" para o leitor brasileiro e outros excertos mais "estrangeirizados" sem, no entanto, distanciar-se do texto-fonte na forma, no conteúdo e no estilo irônico e crítico de McEwan. 


\section{Referências}

MCEWAN, Ian. Enclausurado. Tradução de Jorio Dauster. 1. ed. São Paulo: Companhia das Letras, 2016, 200 p.

MCEWAN, Ian. Nutshell. 1. ed. New York: Nan A. Talese/Doubleday, 2016. $198 \mathrm{p}$.

Recebido em: 19/07/2019

Aceito em: 30/10/2019

Publicado em janeiro de 2020

Marcia Goretti Carvalho. E-mail: marciagoretti@bol.com.br.

ORCID: https://orcid.org/0000-0001-8153-9945 